GRASAS Y ACEITES 68 (1)

January-March 2017, e173

ISSN-L: 0017-3495

doi: http://dx.doi.org/10.3989/gya.0678161

\title{
Detection of olive oil adulteration by low-field NMR relaxometry and $U V$-Vis spectroscopy upon mixing olive oil with various edible oils
}

\author{
S. $\mathrm{Ok}^{\mathrm{a}, \mathrm{b}, \mathbb{}}$ \\ ${ }^{b}$ Petroleum Research Center, Kuwait Institute for Scientific Research, P.O. box 24885 Safat, 13109, Kuwait \\ Correspondence: sok@uos.de
}

Submitted: 22 June 2016; Accepted: 10 October 2016

SUMMARY: Adulteration of olive oil using unhealthy substitutes is considered a threat for public health. Low-field (LF) proton $(1 \mathrm{H})$ nuclear magnetic resonance (NMR) relaxometry and ultra-violet (UV) visible spectroscopy are used to detect adulteration of olive oil. Three different olive oil with different oleoyl acyl contents were mixed with almond, castor, corn, and sesame oils with three volumetric ratios, respectively. In addition, Arbequina olive oil was mixed with canola, flax, grape seed, peanut, soybean, and sunflower seed oils with three volumetric ratios. Transverse magnetization relaxation time $\left(T_{2}\right)$ curves were fitted with bi-exponential decaying functions. $\mathrm{T}_{2}$ times of each mixture of olive oils and castor oils, and olive oils and corn oils changed systematically as a function of volumetric ratio. To detect the adulteration in the mixtures with almond and sesame oils, both $\mathrm{LF}{ }^{1} \mathrm{H}$ NMR relaxometry and UV-Vis spectroscopy were needed, where UV-Vis-spectroscopy detected the adulteration qualitatively. In the mixtures of Arbequina olive oil and flax, peanut, soybean, and sunflower seed oils, both $\mathrm{T}_{21}$ and $\mathrm{T}_{22}$ values became longer systematically as the content of the olive oil was decreased. The unique UV-Vis maximum absorbance of flax oil at $320.0 \mathrm{~nm}$ shows the adulteration of olive oil qualitatively.

KEYWORDS: Adulteration detection; Low-field NMR relaxometry; Olive oil; UV-Vis spectroscopy

RESUMEN: Detección de la adulteración de aceite de oliva mediante relaxometría magnética nuclear de campo bajo y espectroscopía $U V$-Vis sobre mezcla de aceite de oliva con diversos aceites comestibles. La adulteración del aceite de oliva con sustituyentes menos saludables es una amenaza para la salud pública. En este trabajo, la detección de la adulteración del aceite de oliva se demuestra utilizando tanto relaxometría magnética nuclear de campo bajo (LF) de protones $\left({ }^{1} \mathrm{H}\right)(\mathrm{RMN})$ y espectroscopía visible y ultra-violeta (UV). Tres muestras de aceites de oliva con diferentes contenidos en oleico se mezclaron con aceites de almendra, ricino, maíz y sésamo con tres relaciones volumétricas. Además, el de arbequina de California se mezcló con cánola, lino, semilla de uva, cacahuete, soja y aceites de girasol con tres relaciones volumétricas. Las curvas de tiempo de relajación de magnetización transversal (T2) fueron completadas con funciones de decaimiento biexponencial. Los tiempos T2 determinados para cada mezcla de aceite de oliva con ricino y maíz cambian sistemáticamente conforme las relaciones volumétricas. Para detectar la adulteración de los aceites de oliva con aceites de almendra y de sésamo, se necesitan tanto relaxometría LF 1H RMN como la espectroscopía UV-Vis. En las mezclas de aceite de oliva arbequina con aceites de lino, maní, soja y girasol, ambos valores T21 y T22 se hicieron mayores sistemáticamente conforme el porcentaje de aceite de oliva se reduce en la mezcla. El máximo de absorbancia UV-Vis del aceite de lino a 320,0 nm demostrará la adulteración del aceite de oliva cualitativamente.

PALABRAS CLAVE: Aceite de oliva; Detección de adulteración; Espectroscopia UV-Vis; Relaxometría RMN de campo bajo

ORCID ID: Ok S http://orcid.org/0000-0003-1992-7781

Citation/Cómo citar este artículo: Ok S. 2017. Detection of olive oil adulteration by low-field NMR relaxometry and UV-Vis spectroscopy upon mixing olive oil with various edible oils. Grasas Aceites 68, e173. http://dx.doi.org/10.3989/ gya.0678161

Copyright: (C) 2017 CSIC. This is an open-access article distributed under the terms of the Creative Commons Attribution (CC-by) Spain 3.0 License. 


\section{INTRODUCTION}

Olive oil is a "natural fruit juice" obtained from the fruit of Olea europea L. by mechanical or physical procedures (Zamora et al. 2001). The consumption of olive oil has increased recently due to its sensory qualities such as taste and health benefits, namely the reduction of risk factors and prevention of the occurrences of chronic diseases like diabetes and obesity (Rohman and Che Man, 2010; Yang and Irudayaraj, 2001; Mendes et al., 2015). In addition to the increase in olive oil consumption, there are unfortunately malpractices in olive oil production including adulteration. Olive oil is usually adulterated by blending with either pomace olive oil or other cheap edible oils including corn, peanut, and sunflower oils. Such malpractice causes threats and challenges to the suppliers and the health of the ultimate consumers (Gurdeniz and Ozen, 2009; Lizhi et al., 2010). For example, because of the consumption of fake cooking mustard oil, more than forty people died in 1998 in India (Lizhi et al., 2010). Therefore, it is essential to develop viable techniques for detecting adulterated edible oils.

In order to detect olive oil adulteration upon blending olive oil with various oils such as hazelnut oil (Zabaras, 2010), palm oil (Rohman and Che Man, 2010), corn oil (Lizhi et al., 2010), and almond oil (Dourtoglou et al., 2003), different techniques ranging from Fourier Transform (FT) infrared (IR) (Rohman and Che Man, 2010; Gurdeniz and Ozen, 2009) and dielectric spectroscopy (Lizhi et al., 2010) to UV-Vis spectroscopy (Torrecilla et al., 2010a) have been employed. Furthermore, both high- (Smejkalova and Piccolo, 2010; Agiomyrgianaki, 2010) and low-field NMR (Xu, 2014) techniques have been utilized. Besides this, the results of the studies were analyzed by chemometrical approaches such as principal component analysis (PCA) (Gurdeniz and Ozen, 2009; Lizhi, 2010).

In the present contribution, both LF NMR relaxometry and UV-Vis spectroscopy were applied. Recently, LF NMR has been employed in food science as a preferred technique due to its advantages such as being rapid, non-destructive, highly reproducible, and sensitive (Riberio et al., 2014, Hills 2006). UV-Vis spectroscopy was also applied in analyzing olive oil because UV-Vis is a less time consuming method in terms of sample preparation and data processing (Torrecilla, 2010a). It is also easy to monitor the presence of colorants of chlorophylls and the derivatives in olive oil samples by UV-Vis spectroscopy (Torrecilla et al., 2010b; Roca et al., 2010). Edible almond, castor, corn and sesame oils were picked for mixing with three different olive oil samples having different oleoyl acyl contents. Among the three olive oil samples, Arbequina olive oil from California was also mixed with canola, flax, grapeseed, peanut, soybean, and sunflower seed oils with three volumetric ratios. The adulterant oils of interest in the current study are cheaper than olive oil, and have similar densities to that of olive oil. Therefore, it is important to detect olive oil adulteration in particular when olive oil is mixed with such cheap and edible oils. The aim of the present research is to test olive oil adulteration detection by rapid and complementary techniques of LF NMR relaxometry and UV-Vis spectroscopy, when in particular the adulteration is at and above a critical economic level. In achieving this goal, the approach of the current contribution is to develop a general predictive strategy with a larger set of representative signals, which might be applied in common analysis laboratories.

\section{MATERIALS AND METHODS}

\subsection{Samples}

Chloroform was purchased from Sigma-Aldrich with $99.9 \%$ purity. Arbequina and Koroneiki olive oils from California were received as gifts from a Californian company with the production date of March 19, 2014, while French-Nyons olive oil was obtained from a local market in Columbus, Ohio USA, and it was the product of the harvest season in the fall of 2013. The chemical contents of these three olive oils were mentioned previously $(\mathrm{Ok}$, 2016). The other oil samples were purchased from local markets in Columbus, Ohio, USA (Table 1). The geographical origins of these adulterant oils are given in Table 1. Prior to the measurements, all of the olive oil samples were kept at $20{ }^{\circ} \mathrm{C}$ in the dark under continuous air conditioning. The olive oil sample was blended for the LF NMR measurements with the other oil samples by three different volume ratios of olive oil to the corresponding oil (v/v 2:1, 1:1, and 1:2). The transverse magnetization

TABLE 1. List of the oils used for blending with olive oil samples

\begin{tabular}{lll}
\hline Sample & Property as Sold & Origin \\
\hline Almond Oil & - & USA \\
Canola oil & - & USA and Canada \\
Castor Oil & - & India \\
Corn Oil & Pure & USA \\
Flax seed Oil & - & Egypt \\
Grape seed Oil & Pure & Italy \\
Peanut oil & $100 \%$ pure & USA \\
Sesame Oil & Extra virgin & India \\
Soybean oil & pure & USA \\
Sunflower seed oil & $100 \%$ pure & Turkey \\
\hline
\end{tabular}


relaxation time $\left(\mathrm{T}_{2}\right)$ measurements on the LF-NMR instrument made with properly sealed $10 \mathrm{~mm}$ NMR tubes. Mixing was carried out by ultrasonication for three minutes at $25^{\circ} \mathrm{C}$ prior to the measurements. The volumetric ratio of the mixtures for UV-vis spectroscopy measurements was always 1:1.

\section{2. $L F^{1} H$ NMR relaxometry}

LF $\mathrm{T}_{2}$ NMR measurements were performed on a Bruker Minispec mq20 NF Series instrument with a magnetic field strength of $0.47 \mathrm{~T}$ corresponding to a proton resonance frequency of $20 \mathrm{MHz}$ at a magnet temperature of $40{ }^{\circ} \mathrm{C}$. The instrument is equipped with a $10 \mathrm{~mm}$ temperature-variable probe. Transversal $\left(T_{2}\right)$ relaxation was measured using the standard Carr-Pucell-Meiboom-Gill (CPMG) pulse sequence found in the Bruker library. The $\mathrm{T}_{2}$ measurements were conducted with a time delay between the $90^{\circ}$ and $180^{\circ}$ pulses $(\tau)$ of 1.0 ms. Data from 1250 echoes were acquired from 32 scans, and the delay time was chosen long enough, $5^{*} \mathrm{~T}_{1}$, to enable complete decay of the $\mathrm{T}_{2}$ signal (Ok, 2014). The repetition time between two succeeding scans was set to $10 \mathrm{~s}$.

The NMR transverse relaxation data were analyzed as follows: a continuous distribution of $\mathrm{T}_{2}$ exponentials related to fatty acyl contents was fitted for all CPMG using the CONTIN algorithm (Provencher, 1982). This analysis yielded a plot for the continuous $\mathrm{T}_{2}$ distribution. Bi-exponential fitting analysis of $\mathrm{T}_{2}$ relaxation data was performed using Origin 9.1 employing the following equation:

$$
\mathrm{y}=\mathrm{A}_{21} * \exp \left(-\mathrm{x} / \mathrm{T}_{21}\right)+\mathrm{A}_{22} * \exp \left(-\mathrm{x} / \mathrm{T}_{22}\right)(\text { eq.1) }
$$

Where $T_{21}$ and $T_{22}$ are the relaxation components, and $\mathrm{A}_{21}$ and $\mathrm{A}_{22}$ are the corresponding amplitudes. The amplitudes $\mathrm{A}_{21}$ and $\mathrm{A}_{22}$ are directly proportional to the amount of fatty acyl present in the samples. The $\mathrm{T}_{21}$ component was calculated as $\mathrm{A}_{21} /$ $\left(A_{21}+A_{22}\right)$ while $T_{22}$ component was determined as $\mathrm{A}_{22} /\left(\mathrm{A}_{21}+\mathrm{A}_{22}\right)$ (Aursand et al., 2008).

\subsection{UV-Vis spectroscopy}

The absorption spectra of the thermally treated olive oil samples were obtained in the range of 800-234 nm, at $1 \mathrm{~nm}$ resolution, using Shimadzu UV-2401PC UV-Vis Recording Spectrophotometer at $25^{\circ} \mathrm{C}$. Quartz cuvettes were used for obtaining the UV-Vis spectra. $0.05 \mathrm{ml}$ of sample was diluted with $3 \mathrm{ml}$ of $\mathrm{CHCl}_{3}$ prior to the measurement.

\section{RESULTS}

First, the detection of olive oil adulteration was evaluated by fitting transverse magnetization relaxation time $\left(\mathrm{T}_{2}\right)$ of the blended samples (Figure 1, Table 2). Two issues were focused on: bi-exponential fitting of $T_{2}$ relaxation decaying curves and continuous distribution of the relaxation curves obtained by Inverse Laplace transformation. It was shown previously that Arbequina, Koroneiki, and France-Nyons olive oils had approximately $72 \%$, $79 \%$, and $84 \%$ oleoyl acyl contents, respectively (Ok, 2016). This difference in oleoyl acyl contents of the olive oils was reflected in the $\mathrm{T}_{2}$ values. Arbequina olive oil with the lowest oleoyl acyl content had the shortest $T_{2}$ time. Figure 1 shows representative $T_{2}$ decays of Arbequina olive oil, castor oil and their mixtures with v:v/1:1. $T_{2}$ of pure olive oil reached complete decay above $1250 \mathrm{~ms}$, while that of pure castor oil reached complete decay above $440 \mathrm{~ms}$. The $T_{2}$ decay of the mixture of Arbequina olive oil and castor oil with v:v/1:1 showed complete decay above $1000 \mathrm{~ms}$. There is also the effect of the oleoyl acyl fraction in the $T_{2}$ values of the oil mixtures. As can be seen in Table 2, the blends of almond oil and either Arbequina or Koroneiki olive oil, as well as the mixtures of sesame oil and either of the two olive oils did not show significant changes in $T_{21}$ and $\mathrm{T}_{22}$ times with respect to those of pure almond and sesame oils. Changing the volumetric ratio of the two olive oils (Arbequina and Koroneiki) to either almond oil or sesame oil did not affect the ultimate $\mathrm{T}_{21}$ and $\mathrm{T}_{22}$ relaxation values. This was related to the similar densities of the almond, sesame and olive oils. In other words, the fatty acyl fractions in sesame, almond, and olive oils are similar to each other. Thus, changing the volumes in preparing these particular blends did not change the ratios of the fatty acyls in the samples. This in turn led to very close $T_{2}$ relaxation values. However, $T_{21}$ values of the mixtures of France-Nyons olive oil and almond oil were longer than that of pure almond oil, while $\mathrm{T}_{21}$ values of the mixtures of France-Nyons olive oil and sesame oil were shorter than that of pure sesame oil. These examples clearly indicate a difference in the oleoyl acyl contents of olive oil samples as an important factor in following the representative signals of adulterated olive oils. As shown in Figure 2 and listed in Table 2, when olive oil samples were mixed with castor oil, both $T_{21}$ and $T_{22}$ values became shorter as the volumetric ratio of olive oil to castor oil was changed from 2:1 to $1: 1$, and even further to 1:2. This was independent of which olive oil was used for preparing the mixtures. The most interesting result was observed in the case of the mixtures prepared by mixing the olive oil samples with corn oil. Both the $T_{21}$ and $T_{22}$ values became longer as the volumetric ratios of the olive oils to corn oil were increased. However, the two values did not become as long as the ones belonging to the pure corn oil.

Then the adulteration detection of olive oil was analyzed by focusing on data of the mixtures of Arbequina olive oil with the other oils of canola, flax, grape seed, peanut, soybean, and sunflower seed. As listed in Table 2, $T_{21}$ and $T_{22}$ values of the 

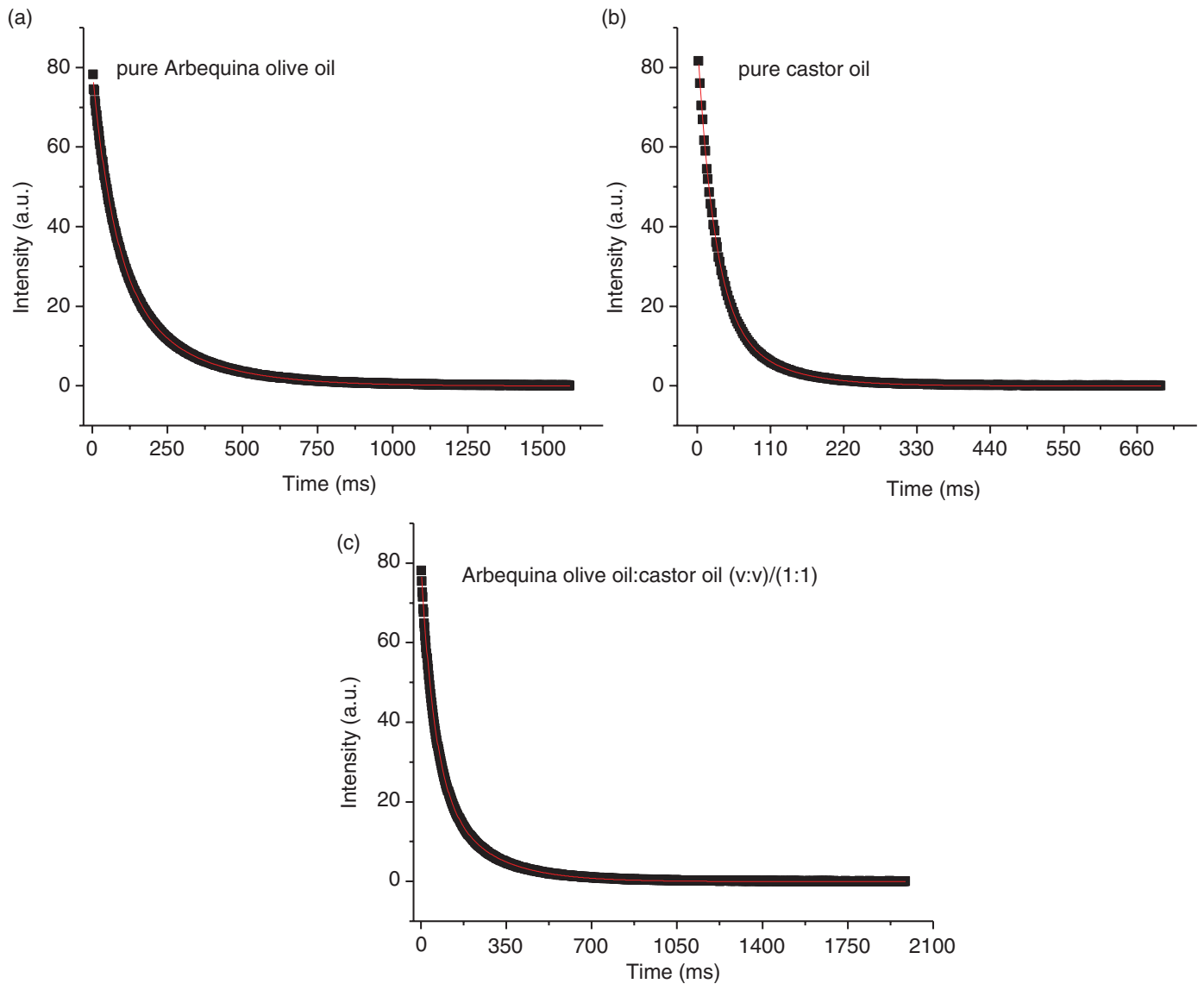

Figure 1. Typical examples of $\mathrm{T}_{2}$ data bi-exponential fittings.

mixtures of Arbequina olive oil and canola oil were shorter than these of pure canola oil. $\mathrm{T}_{21}$ and $\mathrm{T}_{22}$ values did not change when the volumetric ratio of Arbequina olive oil to canola oil varied from 2:1 to $1: 1$, and 1:2. There were no systematic changes in $T_{21}$ or $\mathrm{T}_{22}$ values of the mixtures of Arbequina olive oil and grape seed oil when the volumetric ratios were changed systematically. However, in the mixtures of Arbequina olive oil with the oils of flax, peanut, soybean, and sunflower seed, both $T_{21}$ and $T_{21}$ values were longer than those of pure olive oil, and shorter than those of pure oils. In these mixtures of Arbequina olive oil and flax, peanut, soybean, and sunflower seed oils, both $T_{21}$ and $T_{22}$ values became longer systematically as the percentage of the olive oil was decreased in the mixtures.

Figure 2 shows typical $\mathrm{T}_{2}$ distributions obtained using the Contin software of the pure olive oil samples, castor oil, and blends of each olive oil with the castor oil. Similar results were observed in the case of the other blends (see Figures 3, 4, and 5 showing $\mathrm{T}_{2}$ distributions of olive oil samples with almond, corn, and sesame oils). The distributed exponential approach utilizes a regularization method to the inverse Laplace transformation yielding a continuous distribution of $\mathrm{T}_{2}$ relaxation times (Provencher 1982). Mathematically, the distributed exponential fitting is ill-defined because it is sensitive to the constraints employed (Hansen et al., 2010; Martens and Thybo, 2000). In addition, there is a shorter $\mathrm{T}_{2}$ relaxation component observed in the range of $10-15 \mathrm{~ms}$. This component is usually attributed to a processing artifact arising in the Contin processing step (Aursand et al., 2008). For this reason, this $\mathrm{T}_{2}$ relaxation component in the range of $10-15 \mathrm{~ms}$ is not taken into account in evaluating the $T_{2}$ distribution of the oils.

As shown in Figure 2(a), when the volume of castor oil in the blend with Arbequina olive oil was increased, the relaxation curves shifted toward the $\mathrm{T}_{2}$ distribution curve of pure castor oil systematically. In addition, the peak of pure castor oil at $25 \mathrm{~ms}$ emerged with the two peaks of pure olive oil below $180 \mathrm{~ms}$ giving rise to a single peak at around $60 \mathrm{~ms}$. The peak of pure olive oil at $256 \mathrm{~ms}$ also shifted to shorter values as the amount of castor oil in the blends was increased. These results showed the possibility of monitoring the adulteration of 
TABLE 2. $\mathrm{T}_{2}$ values of oils in their pure state and in blends with olive oil samples

\begin{tabular}{|c|c|c|c|c|c|c|}
\hline Pure oils & $\mathbf{A}_{21}$ & $\mathbf{A}_{22}$ & $\begin{array}{r}\mathrm{T}_{21} \\
(\mathrm{~ms})\end{array}$ & $\begin{array}{l}\mathrm{T}_{22} \\
(\mathrm{~ms}) \\
\end{array}$ & $\begin{array}{c}\% \\
\mathbf{A}_{21} \\
\end{array}$ & $\begin{array}{c}\% \\
\mathbf{A}_{22} \\
\end{array}$ \\
\hline $\begin{array}{l}\text { California- } \\
\text { Arbequina olive oil }\end{array}$ & 30.4 & 47.6 & 231.2 & 73.6 & 39.0 & 61.0 \\
\hline $\begin{array}{l}\text { California- } \\
\text { Koroneiki olive oil }\end{array}$ & 33.2 & 48.5 & 284.5 & 95.2 & 40.6 & 59.4 \\
\hline $\begin{array}{l}\text { France-Nyons } \\
\text { olive oil }\end{array}$ & 34.1 & 49.2 & 285.5 & 94.0 & 40.9 & 59.1 \\
\hline Almond oil & 33.1 & 48.4 & 306.0 & 94.1 & 40.6 & 59.4 \\
\hline Canola oil & 33.1 & 49.3 & 321.0 & 102.2 & 40.2 & 59.8 \\
\hline Castor oil & 21.6 & 65.6 & 78.6 & 25.1 & 24.8 & 75.2 \\
\hline Corn oil & 32.5 & 46.4 & 349.3 & 106.5 & 41.2 & 58.8 \\
\hline Flax oil & 29.3 & 47.4 & 437.7 & 123.0 & 38.2 & 61.8 \\
\hline Grape seed oil & 33.6 & 46.8 & 359.7 & 108.8 & 41.8 & 58.2 \\
\hline Peanut oil & 33.3 & 49.3 & 300.1 & 97.3 & 40.3 & 59.7 \\
\hline Sesame oil & 33.0 & 47.2 & 329.0 & 101.8 & 41.1 & 58.9 \\
\hline Soybean oil & 32.8 & 48.0 & 384.8 & 115.9 & 40.6 & 59.4 \\
\hline Sunflower seed oil & 33.2 & 47.9 & 351.1 & 104.1 & 40.9 & 59.1 \\
\hline \multicolumn{7}{|l|}{ Oil mixtures } \\
\hline \multicolumn{7}{|c|}{ Arbequina olive oil : almond oil (v/v) } \\
\hline $2: 1$ & 32.3 & 47.2 & 302.1 & 98.0 & 40.6 & 59.4 \\
\hline $1: 1$ & 32.2 & 47.6 & 302.3 & 96.5 & 40.4 & 59.6 \\
\hline $1: 2$ & 32.1 & 47.4 & 311.3 & 98.2 & 40.4 & 59.6 \\
\hline \multicolumn{7}{|c|}{ Arbequina olive oil : canola oil (v/v) } \\
\hline $2: 1$ & 31.8 & 50.0 & 303.7 & 95.0 & 38.9 & 61.1 \\
\hline $1: 1$ & 31.9 & 50.7 & 307.1 & 94.7 & 38.6 & 61.4 \\
\hline $1: 2$ & 32.0 & 49.9 & 306.1 & 95.3 & 39.1 & 60.9 \\
\hline \multicolumn{7}{|c|}{ Arbequina olive oil : castor oil (v/v) } \\
\hline $2: 1$ & 29.9 & 49.2 & 227.8 & 68.3 & 37.8 & 62.2 \\
\hline $1: 1$ & 27.5 & 51.5 & 201.4 & 55.3 & 34.8 & 65.2 \\
\hline $1: 2$ & 24.1 & 54.0 & 165.7 & 46.5 & 30.9 & 69.1 \\
\hline \multicolumn{7}{|c|}{ Arbequina olive oil : corn oil (v/v) } \\
\hline $2: 1$ & 32.1 & 48.4 & 277.1 & 88.2 & 39.9 & 60.1 \\
\hline $1: 1$ & 32.5 & 48.4 & 306.2 & 96.1 & 40.2 & 59.8 \\
\hline $1: 2$ & 32.1 & 48.1 & 308.5 & 95.3 & 40.0 & 60.0 \\
\hline \multicolumn{7}{|c|}{ Arbequina olive oil : flax oil (v/v) } \\
\hline $2: 1$ & 30.3 & 48.7 & 332.5 & 103.5 & 38.4 & 61.6 \\
\hline $1: 1$ & 29.6 & 48.8 & 370.6 & 111.8 & 37.8 & 62.2 \\
\hline $1: 2$ & 28.9 & 49.1 & 377.1 & 109.2 & 37.1 & 62.9 \\
\hline \multicolumn{7}{|c|}{ Arbequina olive oil : grape seed oil (v/v) } \\
\hline $2: 1$ & 32.0 & 47.5 & 327.2 & 108.8 & 40.3 & 59.7 \\
\hline $1: 1$ & 31.9 & 47.8 & 334.5 & 103.2 & 40.0 & 60.0 \\
\hline $1: 2$ & 33.1 & 48.2 & 320.5 & 98.7 & 40.7 & 59.3 \\
\hline \multicolumn{7}{|c|}{ Arbequina olive oil : peanut oil (v/v) } \\
\hline $2: 1$ & 32.3 & 48.6 & 283.1 & 90.9 & 39.9 & 60.1 \\
\hline $1: 1$ & 33.2 & 50.6 & 285.1 & 91.0 & 39.6 & 60.4 \\
\hline $1: 2$ & 32.9 & 49.7 & 295.8 & 94.9 & 39.8 & 60.2 \\
\hline
\end{tabular}

TABLE 2. (Continued)

\begin{tabular}{|c|c|c|c|c|c|c|}
\hline Pure oils & $\mathbf{A}_{21}$ & $\mathbf{A}_{22}$ & $\begin{array}{l}\mathrm{T}_{21} \\
(\mathrm{~ms})\end{array}$ & $\begin{array}{c}\mathrm{T}_{22} \\
(\mathrm{~ms})\end{array}$ & $\begin{array}{c}\% \\
\mathbf{A}_{21} \\
\end{array}$ & $\begin{array}{c}\% \\
\mathbf{A}_{22} \\
\end{array}$ \\
\hline \multicolumn{7}{|c|}{ Arbequina olive oil : sesame oil (v/v) } \\
\hline $2: 1$ & 33.0 & 47.8 & 329.0 & 101.8 & 40.8 & 59.2 \\
\hline $1: 1$ & 32.3 & 48.3 & 288.8 & 91.1 & 40.1 & 59.9 \\
\hline $1: 2$ & 32.3 & 47.5 & 303.5 & 95.1 & 40.5 & 59.5 \\
\hline
\end{tabular}

Arbequina olive oil : soybean oil (v/v)

$\begin{array}{lllllll}2: 1 & 32.1 & 49.3 & 308.9 & 96.9 & 39.4 & 60.6 \\ 1: 1 & 31.7 & 49.1 & 320.3 & 98.5 & 39.2 & 60.8 \\ 1: 2 & 32.8 & 50.1 & 347.0 & 105.6 & 39.6 & 60.4\end{array}$

Arbequina olive oil : sunflower seed oil (v/v)

\begin{tabular}{lrrrrrr}
$2: 1$ & 32.6 & 48.6 & 299.9 & 95.3 & 40.1 & 59.9 \\
$1: 1$ & 31.0 & 47.2 & 277.4 & 85.4 & 39.6 & 60.4 \\
$1: 2$ & 31.8 & 47.3 & 320.0 & 98.5 & 40.2 & 59.8 \\
\multicolumn{5}{r}{ Koroneiki olive oil : almond oil (v/v) } \\
$2: 1$ & 32.3 & 50.4 & 308.6 & 96.8 & 39.1 & 60.9 \\
$1: 1$ & 31.8 & 49.9 & 313.2 & 96.0 & 38.9 & 61.1 \\
$1: 2$ & 32.6 & 50.1 & 302.3 & 92.6 & 39.4 & 60.6
\end{tabular}

Koroneiki olive oil : castor oil (v/v)

$\begin{array}{lllllll}2: 1 & 33.3 & 48.8 & 234.9 & 62.4 & 40.6 & 59.4 \\ 1: 1 & 28.6 & 51.7 & 196.1 & 45.9 & 35.6 & 64.4 \\ 1: 2 & 26.2 & 55.1 & 156.2 & 37.6 & 32.2 & 67.8\end{array}$

Koroneiki olive oil : corn oil (v/v)

$\begin{array}{lllllll}2: 1 & 33.2 & 49.7 & 302.6 & 96.2 & 40.0 & 60.0 \\ 1: 1 & 32.9 & 49.4 & 314.6 & 98.2 & 40.0 & 60.0 \\ 1: 2 & 33.0 & 49.3 & 325.7 & 99.9 & 40.1 & 59.9\end{array}$

Koroneiki olive oil : sesame oil (v/v)

$\begin{array}{ccccccc}2: 1 & 32.1 & 51.5 & 299.1 & 91.0 & 38.4 & 61.6 \\ 1: 1 & 31.7 & 50.1 & 337.9 & 102.6 & 38.8 & 61.2 \\ 1: 2 & 32.6 & 50.6 & 325.5 & 97.7 & 39.2 & 60.8\end{array}$

France (Nyons) olive oil : almond oil (v/v)

$\begin{array}{lcccccc}2: 1 & 32.1 & 51.5 & 299.1 & 91.0 & 38.4 & 61.6 \\ 1: 1 & 31.7 & 50.1 & 337.9 & 102.6 & 38.8 & 61.2 \\ 1: 2 & 32.6 & 50.6 & 325.5 & 97.7 & 39.2 & 60.8\end{array}$

France (Nyons) olive oil : castor oil (v/v)

$\begin{array}{lllllll}2: 1 & 34.3 & 49.5 & 213.7 & 57.9 & 40.9 & 59.1 \\ 1: 1 & 31.5 & 49.9 & 188.9 & 45.0 & 38.7 & 61.3 \\ 1: 2 & 25.3 & 55.2 & 164.0 & 36.7 & 31.4 & 68.6\end{array}$

France (Nyons) olive oil : corn oil (v/v)

$\begin{array}{lcccccc}2: 1 & 32.6 & 50.0 & 296.7 & 93.8 & 39.5 & 60.5 \\ 1: 1 & 29.9 & 48.7 & 322.5 & 100.3 & 38.0 & 62.0 \\ 1: 2 & 33.0 & 49.1 & 317.9 & 97.5 & 40.2 & 59.8\end{array}$

France (Nyons) olive oil : sesame oil (v/v)

\begin{tabular}{lllllll}
$2: 1$ & 32.9 & 49.2 & 308.2 & 97.8 & 40.1 & 59.9 \\
$1: 1$ & 32.9 & 49.1 & 311.3 & 97.9 & 40.1 & 59.9 \\
$1: 2$ & 33.0 & 48.9 & 308.4 & 95.7 & 40.3 & 59.7 \\
\hline
\end{tabular}



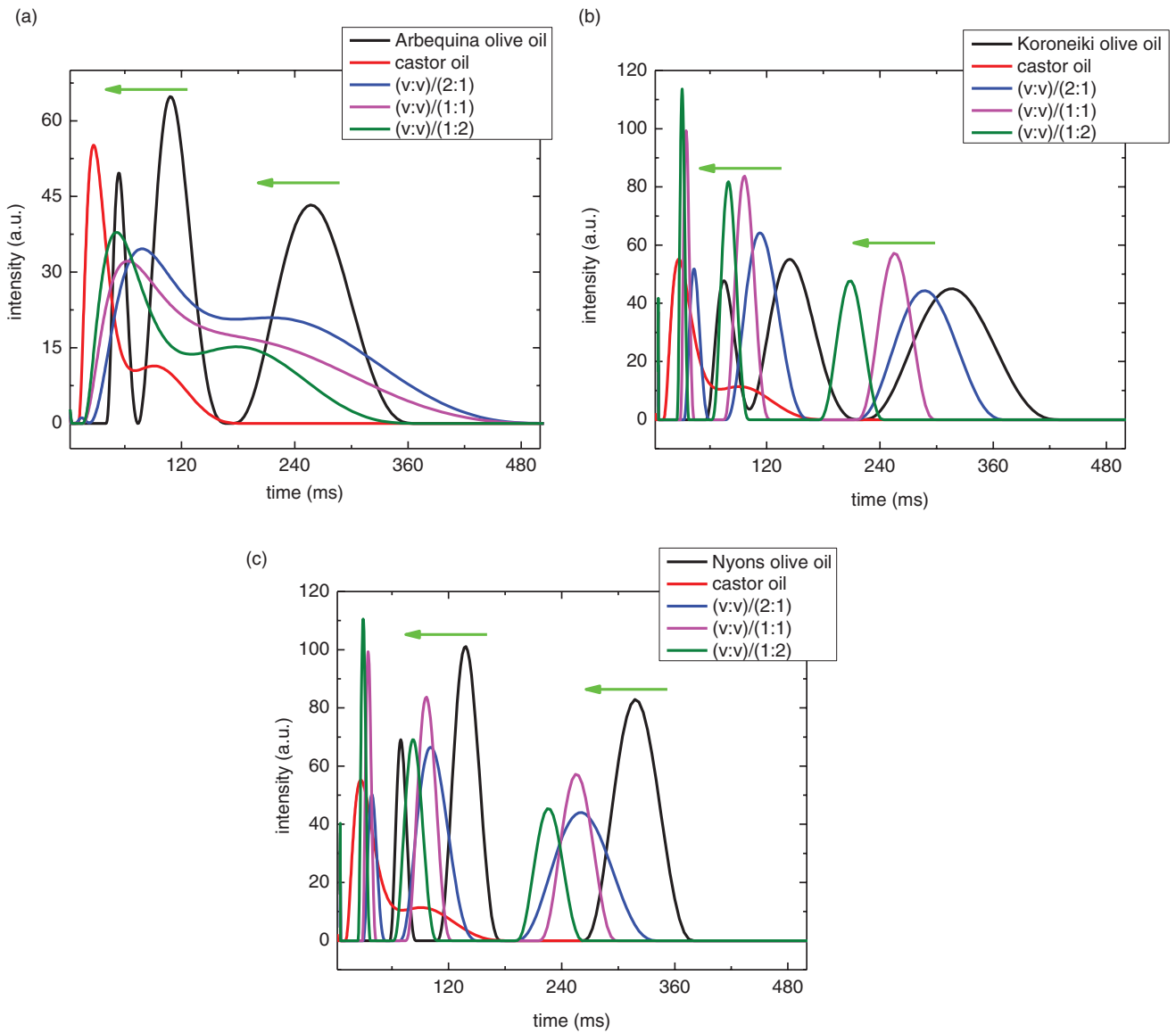

Figure 2 (a-c) Continuous T2 relaxation time data belonging to: Arbequina olive oil, castor oil, and their mixtures (a); Koroneiki olive oil, castor oil, and their mixtures (b); Nyons olive oil, castor oil, and their mixtures (c).

olive oil by $\mathrm{T}_{2}$ relaxation distributions. In addition, as shown in Figure 2(b,c), both of the two signals of Koroneiki and France-Nyons olive oils around $70 \mathrm{~ms}$ and $140 \mathrm{~ms}$ started shifting towards the pure castor oil peak at $25 \mathrm{~ms}$. The signal at $318 \mathrm{~ms}$ of the two olive oils also shifted towards $93 \mathrm{~ms}$ of the pure castor oil. Besides $\mathrm{T}_{2}$ distribution analysis of olive oils with castor oil, as indicated in the supporting figures, $\mathrm{T}_{2}$ distribution curves of the three olive oils in mixtures with almond, corn, and sesame oils were analyzed (see Figures 3, 4, and 5 showing $T_{2}$ distributions of olive oil samples with almond, corn, and sesame oils). In the $\mathrm{T}_{2}$ distribution curves belonging to the mixtures of Arbequina olive oil and almond oil, $T_{2}$ peaks of olive oil broadened and overlapped with the $T_{2}$ peaks of the pure almond oil. In the case of Koroneiki and FranceNyons olive oils, the intensity of the $T_{2}$ peak at $318 \mathrm{~ms}$ belonging to the pure olive oils decreased, and started shifting towards higher values. In the mixtures of Arbequina olive oil with either corn or sesame oil (Figures 4 and 5), the number of $T_{2}$ peaks of pure Arbequina olive oil decreased to two. Both of these two peaks also broadened. The one around $310 \mathrm{~ms}$ started shifting towards the $350 \mathrm{~ms}$ peak of the pure corn and sesame oils. When either Koroneiki or France-Nyons olive oil was mixed with either corn or sesame oil, the number of $T_{2}$ peaks remained the same before and after preparing the mixtures. The two peaks at around $70 \mathrm{~ms}$ and $140 \mathrm{~ms}$ did not show a significant change in their positions in the $T_{2}$ distribution curves of the mixtures with respect to the curves of the pure state. However, the third peak around $318 \mathrm{~ms}$ of Koroneiki and France-Nyons olive oils did not indicate a systematic shift towards the peak of pure sesame oil at around $310 \mathrm{~ms}$.

Upon careful analysis and comparison of $\mathrm{T}_{2}$ distributions for each pair of olive oil and either of the almond, castor, corn, and sesame oils, the continuous $T_{2}$ distribution curves obtained by Inverse Laplace transformation and belonging to the mixtures prepared by mixing Arbequina olive oil with either canola, peanut, or soybean oil as representative data (Figure 6 (a-c)). Firstly, the number of $\mathrm{T}_{2}$ peaks in the $\mathrm{T}_{2}$ distribution curves of Arbequina olive oil remained the same in the curves of the mixtures of Arbequina olive oil with either the canola, peanut, or soybean oil. Secondly, the mixtures of Arbequina olive oil with either peanut or soybean 

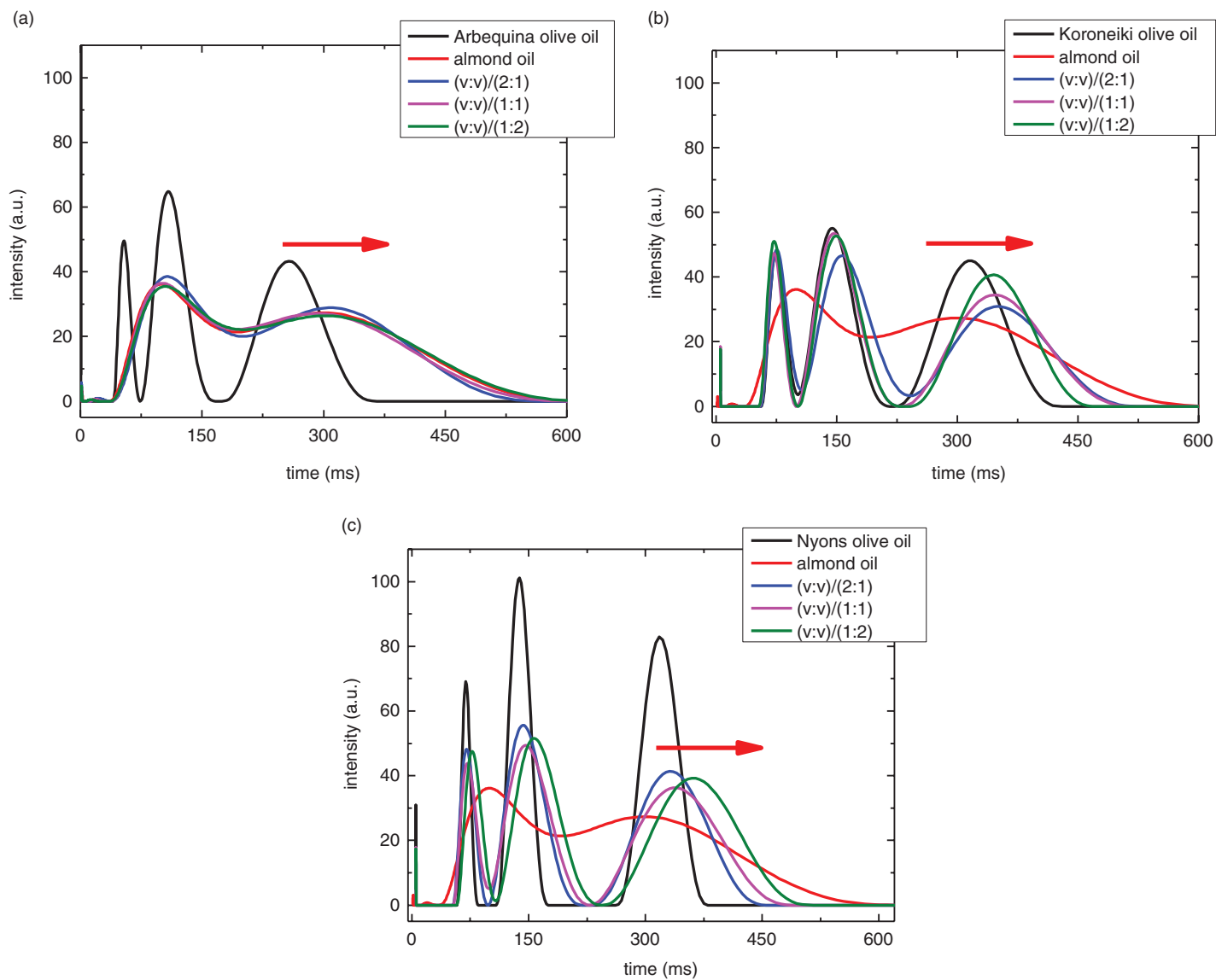

FIgURE 3 (a-c) Continuous T2 relaxation time data belonging to Arbequina olive oil, almond oil, and their mixtures (a); Koroneiki olive oil, almond oil, and their mixtures (b); Nyons olive oil, almond oil, and their mixtures (c).

oil yielded practically the same $\mathrm{T}_{2}$ distributions. On the other hand, the appearance of $\mathrm{T}_{2}$ distributions of the mixtures of Arbequina olive oil and canola oil look similar to those of the mixtures of Arbequina olive oil with either peanut or soybean oil. However, the $T_{2}$ distributions of the mixtures of Arbequina olive oil and canola oil had $\mathrm{T}_{2}$ peaks with lower intensity and broader distribution. These $\mathrm{T}_{2}$ distribution results in the case of the mixtures of Arbequina olive oil with either canola, peanut, or soybean oil clearly indicated that the possible adulteration detection needs to be further confirmed by other techniques such as UV-Vis spectroscopy.

The UV activity of olive oil arises from two types of natural pigments: chlorophylls and carotenoids (Minguez-Mosquera, 1997). The green hues of the oils are attributed to the existence of chlorophyll pigments, while the yellow hues come from carotenoids. Further, chlorophyll pigments are composed of tetrapyrole macrocycle and several conjugated double bonds, while carotenoids are isoprenoid compounds having a hydrocarbon structure with conjugated double bonds. The conjugated double bonds are responsible for the absorption in the visible region of the spectrum of these segments (Moyano et al., 2010). For example, the specific extinction coefficient at $268 \mathrm{~nm}$ corresponds to the maximum absorption of the conjugated trienes (Passaloglou-Emmanouilidou, 1990). There are several derivatives of chlorophyll pigments such as chlorophyll a, chlorophyll b, pheophytins, chlorophyllides, and pheophorbides (Minguez-Mosquera, 1997). There were no quantitative differences in the chlorophyll pigment percentage of the olive oils obtained from different olive cultivars produced in various countries (Giuliani et al., 2011). Some researchers also identified qualitative differences in olive oil in terms of evidence of chlorophyll pigments (Cerretani et al., 2008; Criado et al., 2007). UV-Vis spectral results were also combined with a chemometric analysis (Torrecilla et al., 2010 (a)), and multivariate calibration (Fuentes et al., 2012). In the current contribution UV-Vis spectroscopy was employed as a qualitative and complementary tool to the $\mathrm{LF}^{1} \mathrm{H}$ NMR method. Figure 7 compares the UV-Vis spectra of pure Arbequina olive oil, castor oil, and mixtures of the two oils with (v:v/1:1). 

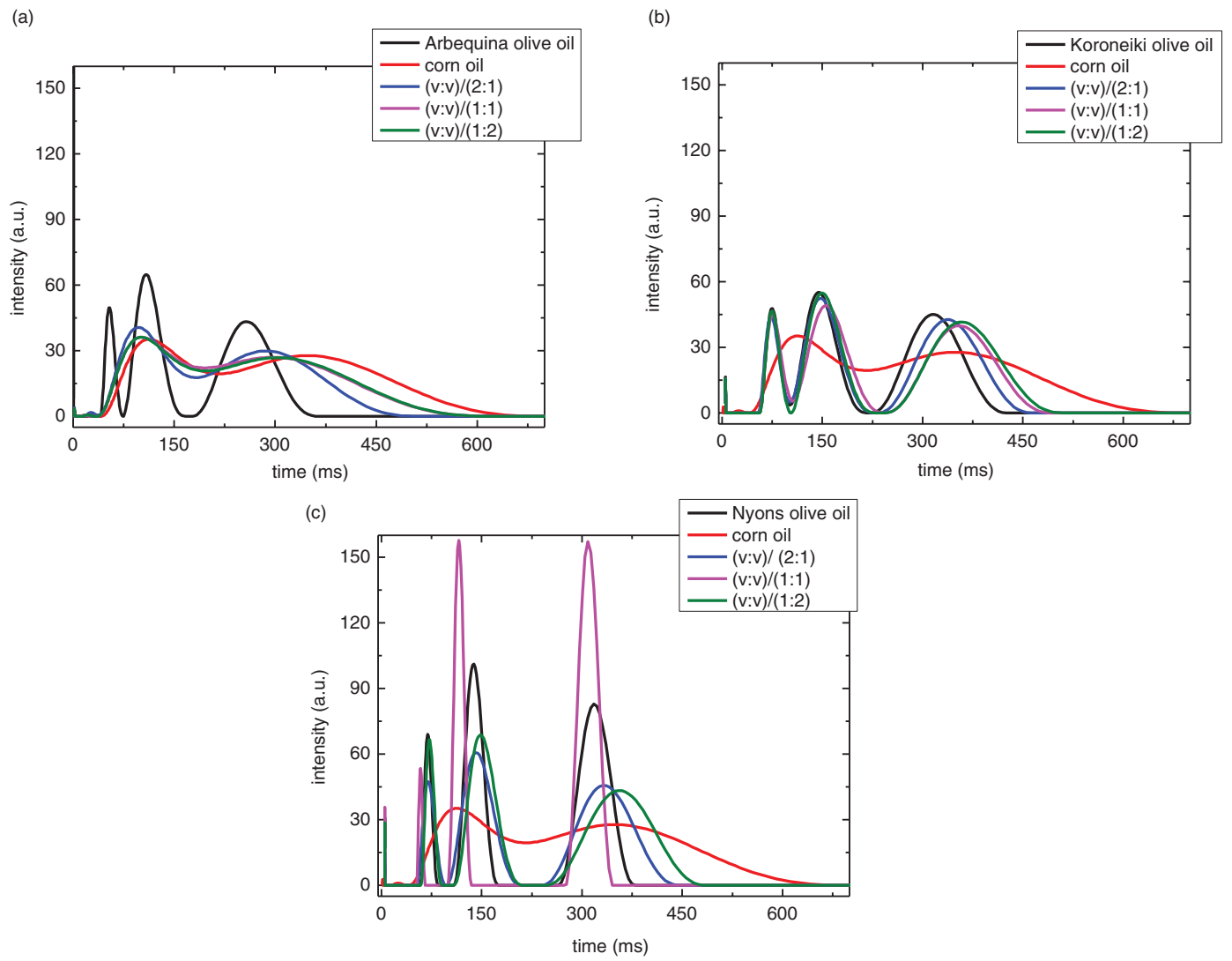

FIgURE 4 (a-c) Continuous T2 relaxation time data belonging to Arbequina olive oil, corn oil, and their mixtures (a); Koroneiki olive oil, corn oil, and their mixtures (b); Nyons olive oil, corn oil, and their mixtures (c).

The maximum absorbance values $\left(\lambda_{\text {nm }}\right)$ of the UV-Vis spectra of the oils either in pure state or in mixtures with olive oil are also given (Table 3).

The common maximum absorbance values in the UV-Vis spectra are approximately at $244.0 \mathrm{~nm}$ and attributed to elenolic acid, a compound significant in concentration in the phenolic fraction of olive oil, and $282.0 \mathrm{~nm}$ to phenolic compounds (tyrosol, hydroxytirosol, and tocopherols) (Fuentes et al., 2012). The oils other than olive oil have a common peak at around $272.0 \mathrm{~nm}$ arising from syringic acid, which is a phenolic compound, while the peak around $260.0-265.0 \mathrm{~nm}$ and observed in the spectra of Koroneiki, France-Nyons olive oils and in castor, corn, soybean and sunflower seed oils was explained by the presence of phenolic compounds, vanilic acid, and protocatechuic acid (Zhang et al., 2013). Flax seed oil has a unique band around at $320.0 \mathrm{~nm}$, which is linked to the existence of some flavonoids like apigenin and luteolin (LermaGarcia et al., 2009). The unique peak of canola and soybean oils at $298.0 \mathrm{~nm}$ was explained by the existence of sinapic acid (Khattab et al., 2010). The unique peak of olive oil with lower intensity around $414.0 \mathrm{~nm}$ was explained by the presence of pheophorbide $b$, which is a chrolophyll derivative, and the peak at $660.0 \mathrm{~nm}$ was attributed to chlorophyll a (Roca et al., 2010; Giuliani et al., 2011). The differences in the maximum absorbance of the UV-Vis spectra of the oil blends with respect to their pure state show that UV-Vis spectroscopy is useful in detecting adulteration in olive oil.

Based on the UV-Vis spectral assignments, it is possible to suggest that in the case of possible adulteration of olive oil samples with almond oil, the unique maximum absorbance of almond oil at $273.0 \mathrm{~nm}$ shows the adulteration qualitatively. In addition to the adulteration detection of castor oil added olive oil by LF-NMR, UV-V is a signal of castor oil at around $273.0 \mathrm{~nm}$ and will also prove the adulteration of olive oil with castor oil. Similar to these cases, the addition of corn oil into olive oils might be detected by UV-Vis spectroscopy with the presence of the signal around $273.0 \mathrm{~nm}$. In the case of the mixtures prepared by mixing an olive oil sample with sesame oil, the maximum absorbance values of olive oil and sesame oil in the region between $260.0 \mathrm{~nm}$ and $285.0 \mathrm{~nm}$ emerged, and yielded one peak in that region. This also helps with the possible adulteration detection of olive oil when the olive oil is mixed with sesame oil. Then the UV-Vis spectra of Arbequina olive oil mixtures 

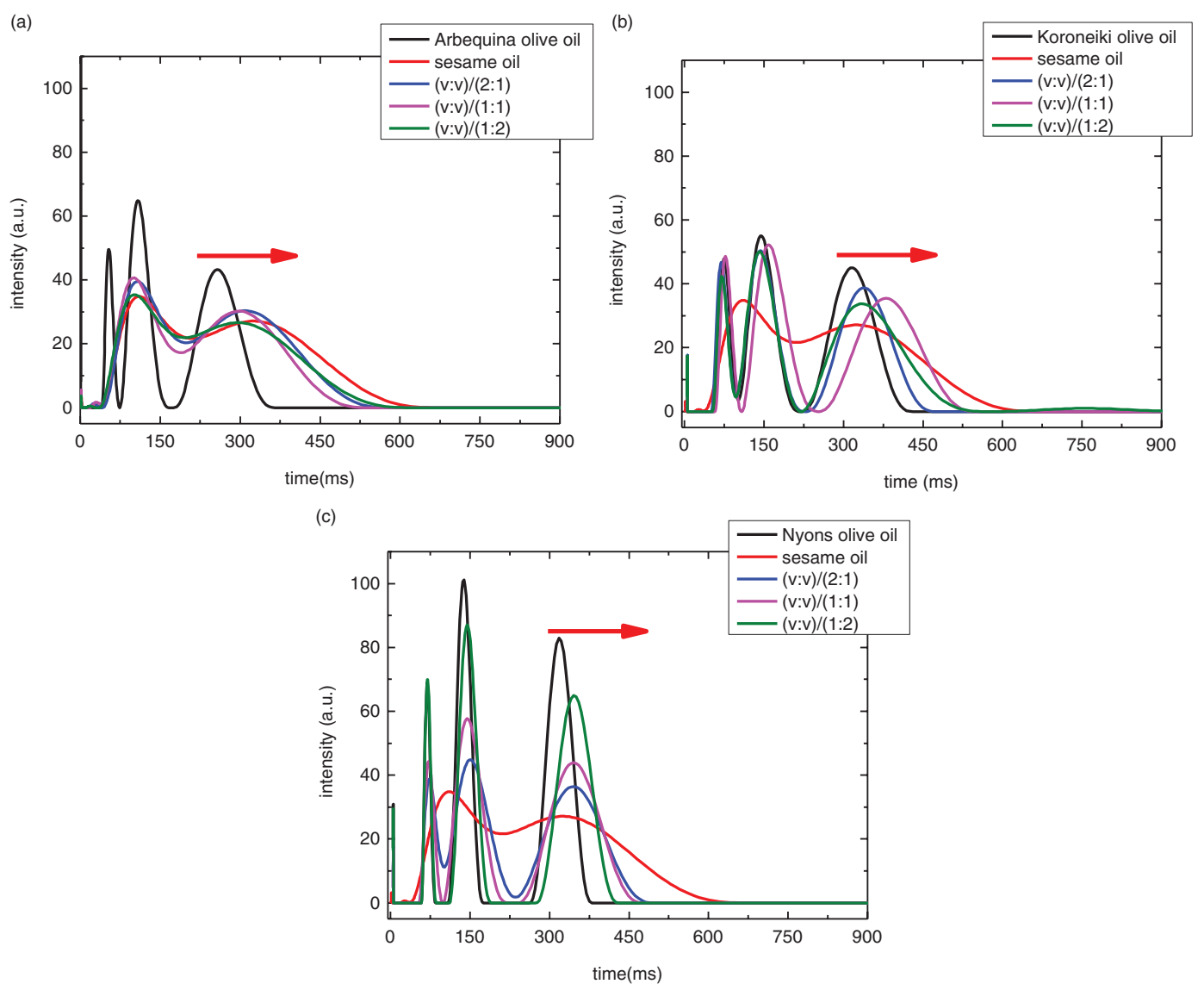

Figure 5 (a-c) Continuous T2 relaxation time data belonging to Arbequina olive oil, sesame oil, and their mixtures (a); Koroneiki olive oil, sesame oil, and their mixtures (b); Nyons olive oil, sesame oil, and their mixtures (c).

with canola, flax, grape seed, peanut, and soybean oils were analyzed. When olive oil was adulterated with flax seed oil, it was possible to detect the adulteration with the unique maximum absorbance at $320.0 \mathrm{~nm}$ of flax seed oil UV-Vis spectrum. In the possible adulteration detection of olive oil upon mixing olive oil with grape seed oil and sunflower oil, the maximum absorbance at $272.0 \mathrm{~nm}$ belonging to grape seed and sunflower oils will be useful in detecting the possible adulteration. The two maximum absorbance values at $267.5 \mathrm{~nm}$ and $277.0 \mathrm{~nm}$ of soybean oil UV-Vis soybean oil UV-Vis spectrum might be also utilized in proving the adulteration of olive oil samples. The unique maximum absorbance of canola and soybean oils at $298.0 \mathrm{~nm}$ makes it easy to detect the adulteration of olive oil when olive oil is mixed with either canola or soybean oil.

\section{DISCUSSION}

One of the major issues related to adulteration detection of natural products such as olive oil is intrinsic variability of both the examined olive oils and the adulterant oils. The intrinsic parameters such as free fatty acids (Nunes, 2014) of edible oils could depend on different factors including geographical origin. In particular for determining the minor constituents of edible oils with less than $1-2 \%$, isolation might be needed (Zamora et al., 2001). However, in the current study, even the different oleoyl acyl contents of different olive oils, California-Arbequina and France-Nyons olive oils namely, were reflected in the $T_{2}$ decaying curves. Different properties such as viscosity of the adulterant oils led also to different $T_{2}$ relaxation times as shown in Table 2. Besides these, it is possible to detect the colorant molecules of both the olive oil samples and the other oils directly with UV-Vis spectroscopy without any isolation. Therefore, combining LF ${ }^{1} \mathrm{H}$ NMR and UV-Vis spectroscopy does not require focusing on the intrinsic variability of the oils, in particular the minor components while analyzing the adulteration detection.

There have been various contributions regarding the detection of olive oil adulteration by several techniques. For example, Mendes et al., (2015) studied near-infrared (IR) and mid-IR in addition to Raman spectroscopy in detecting olive oil adulteration with soybean oil of several adulterant 

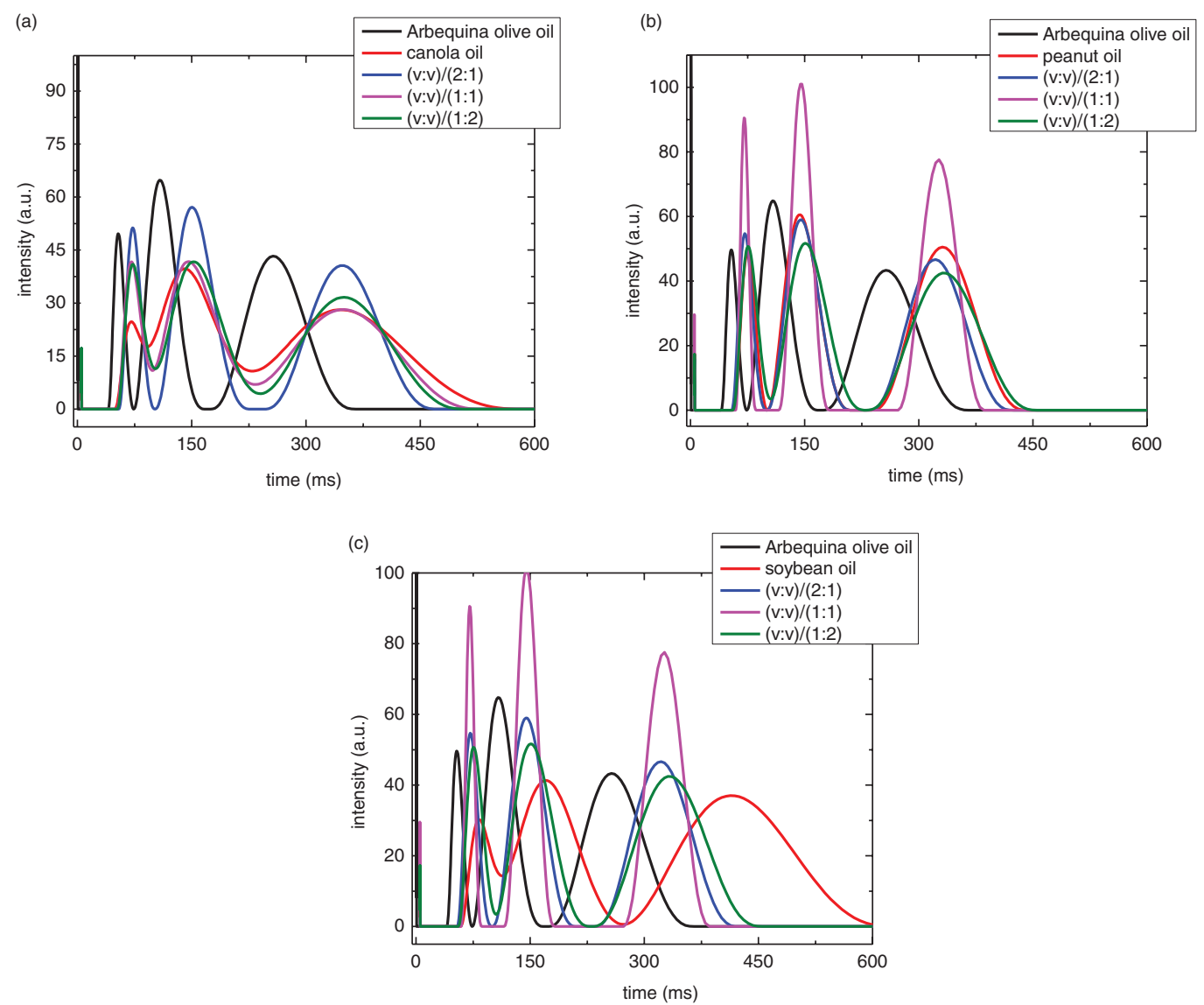

Figure 6. Continuous T2 relaxation data of Arbequina olive oil, and its mixtures with canola oil (a); peanut oil (b); soybean oil (c).

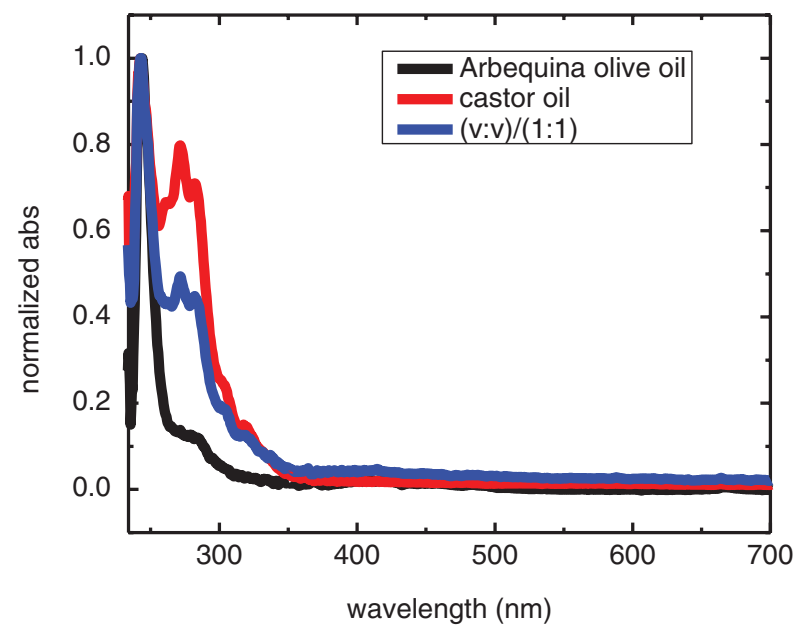

FIGURE 7. The representative UV-Vis spectra of pure olive oil, pure castor oil, and the blends of them.

levels from zero to $100 \%$, while Gurdeniz and Ozen (2009) focused on combining chemometric analysis with mid-IR for analyzing adulteration of olive oil samples mixed with either rapeseed, cottonseed, and a corn-sunflower binary mixture. Further, Yang and Irudayaraj (2001) also combined near-IR, fourier-transformation (FT)-IR, and FT-Raman techniques for determining pomace olive oil adulteration in extra virgin olive oil. Rohman and Che Man (2010) used FT-IR for olive oil adulteration detection but mainly by mixing olive oil with palm oil. Among such contributions, Gurdeniz and Ozen (2009) showed that the manipulation of mid-IR spectra with chemometrics led to the detection and the quantification of olive oil adulteration. They also found that the detection limit for the adulterant oil or the binary oil mixture was at $5 \%$. In the study by Smejkalova and Piccelo (2010), the potential of a high-power pulse-field gradient (PFG) NMR probe was used for detecting adulterated extra virgin olive oils. PFG NMR was employed for analyzing olive oil with adulterant oils of soybean, sunflower, peanut, and hazelnut. It was shown that combining PFG NMR with a multivariate classification method resulted in successful discrimination of authentic and high adulterated extra virgin olive oil with hazelnut oil (as low as 30\%), peanut oil (as low as $30 \%$ ), with soybean oil (as low as $10 \%$ ), and sunflower oils (as low as 10\%). Agiomyrgianaki 
TABLE 3. Maximum absorbance values of the UV-Vis bands of the oils of interest

\begin{tabular}{|c|c|c|c|c|c|c|}
\hline & $\lambda_{1}(\mathrm{~nm})$ & $\lambda_{2}(\mathrm{~nm})$ & $\lambda_{3}(\mathrm{~nm})$ & $\lambda_{4}(\mathrm{~nm})$ & $\lambda_{5}(\mathrm{~nm})$ & $\lambda_{6}(\mathrm{~nm})$ \\
\hline \multicolumn{7}{|l|}{ Pure oils } \\
\hline Arbequina-California & 244.0 & 281.0 & 411.5 & 664.0 & - & - \\
\hline Koroneiki-California & 243.0 & 264.5 & 403.0 & 664.0 & - & - \\
\hline France (Nyons) & 245.5 & 265.0 & 400.0 & 660.5 & - & - \\
\hline Almond oil & 244.0 & 273.0 & 284.0 & - & - & - \\
\hline Canola oil & 245.0 & 278.5 & 298.0 & - & - & - \\
\hline Castor oil & 244.0 & 260.0 & 271.0 & 282.0 & - & - \\
\hline Corn oil & 244.0 & 260.0 & 272.0 & 282.0 & - & - \\
\hline Flax seed oil & 272.0 & 282.0 & 320.0 & - & - & - \\
\hline Grape seed oil & 262.0 & 272.0 & 282.0 & - & - & - \\
\hline Peanut oil & 243.5 & 269.5 & - & - & - & - \\
\hline Sesame oil & 244.0 & 272.0 & 284.0 & - & - & - \\
\hline Soybean oil & 243.0 & 265.5 & 278.0 & 298.0 & - & - \\
\hline Sunflower seed oil & 250.0 & 261.0 & 272.0 & 283.0 & - & - \\
\hline \multicolumn{7}{|l|}{ Oil Mixtures (v:v/1:1) } \\
\hline Arbequina-California: almond oil & 244.0 & 273.0 & 284.0 & 410.0 & 661.0 & - \\
\hline Arbequina-California: canola oil & 245.0 & 276.0 & 298.0 & 401.5 & 660.5 & - \\
\hline Arbequina-California: castor oil & 244.0 & 260.0 & 271.0 & 282.0 & 410.0 & 664.0 \\
\hline Arbequina-California: corn oil & 244.0 & 260.0 & 272.0 & 282.0 & 410.0 & 664.0 \\
\hline Arbequina-California: flax seed oil & 272.0 & 282.0 & 320.0 & 410.0 & 664.0 & - \\
\hline Arbequina-California: grape seed oil & 262.0 & 272.0 & 282.0 & 410.0 & 665.0 & - \\
\hline Arbequina-California: peanut oil & 244.0 & 266.5 & 276.0 & 398.5 & 663.0 & - \\
\hline Arbequina-California: sesame oil & 244.0 & 272.0 & 411.0 & 664.5 & - & - \\
\hline Arbequina-California: soybean oil & 247.0 & 267.5 & 277.0 & 298.0 & 398.5 & 664.0 \\
\hline Arbequina-California: sunflower seed oil & 245.0 & 272.0 & 283.0 & 412.5 & 664.0 & - \\
\hline Koroneiki-California: almond oil & 247.5 & 264.0 & 272.5 & 376.5 & 662.5 & - \\
\hline Koroneiki-California: castor oil & 242.0 & 265.5 & 275.0 & 399.5 & 661.5 & - \\
\hline Koroneiki-California: corn oil & 244.0 & 261.5 & 275.0 & 403.0 & 662.0 & - \\
\hline Koroneiki-California: sesame oil & 247.5 & 277.0 & 662.5 & - & - & - \\
\hline France (Nyons): almond oil & 245.5 & 272.5 & 282.0 & 657.0 & & - \\
\hline France (Nyons): castor oil & 243.0 & 262.0 & 274.5 & 308.0 & 658.0 & - \\
\hline France (Nyons): corn oil & 244.0 & 256.5 & 277.0 & 659.5 & - & - \\
\hline France (Nyons): sesame oil & 248.0 & 280.5 & 661.0 & - & - & - \\
\hline
\end{tabular}

et al. (2010) also focused on the detection of olive oil adulteration with hazelnut oil by applying ${ }^{1} \mathrm{H}$ and ${ }^{31} \mathrm{P}$ NMR techniques in conjunction with multivariate statistical analyses of canonical discriminant analysis (CDA) and classification binary trees (CBTs). Both of the statistical techniques were successful in grouping the adulterated samples correctly. Xu et al. (2014) used $\mathrm{LF}^{1} \mathrm{H}$ unilateral NMR for the detection of virgin olive oil adulteration where olive oil was mixed with sunflower and red palm oils. Xu and co-workers measured the transverse relaxation and diffusion coefficients of different adulterated oils in analyzing the adulteration detection of olive oil.
There are several knowledge gaps in the literature studies mentioned above. Firstly, the number of olive oil and edible oil mixtures analyzed in these studies was limited. Secondly, the number of studies on the adulteration detection of olive oil when it is mixed with either castor oil or flax seed oil is scarce. The current report fills this gap of scarce data on adulteration detection of olive oil when the adulterant oil could be either castor or flax seed oil. Furthermore, it is important to show the adulteration detection of olive oil when the adulteration is at economically significant levels. In the present study, the possibility of olive oil adulteration detection is also shown in particular when an olive oil 
sample is mixed with other edible oils at economically significant ratios. Moreover, in the techniques such as FT-IR, there is not a significant difference in the signals of pure and adulterated olive oils. For example, signals of $\mathrm{C}=\mathrm{O}$ and $\mathrm{C}-\mathrm{H}$ may arise from organic constituents of any edible oil. Hence, FT-IR signals of olive oil and the adulterant oil will overlap even at lower levels of adulteration. This clearly shows the need for finding representative signals by methods such as $\mathrm{LF}^{1} \mathrm{H}$ NMR in adulteration detection of olive oil. Besides filling such knowledge gaps in olive oil adulteration detection studies, it is also essential to use complementary methods rather than techniques which provide similar information.

In the present study, the detection of adulteration up to $66 \%$ with, for instance, castor oil was shown. This limit has significance because it is much higher than the economically significant level. This demonstrates that $\mathrm{LF}{ }^{1} \mathrm{H}$ NMR has the advantage of detecting adulterated olive oil where the adulterant oil has an economically important fraction in the mixture. This might be defined as lower critical limit (LCL) for adulterated olive oil detection in an economic sense. Below this limit, adulteration perhaps will not be economically preferable. In other words, the employed method needs to determine the adulteration of olive oil above the lower critical limit. The obtained results by $\mathrm{LF}{ }^{1} \mathrm{H}$ unilateral NMR showed detection of adulterations of olive oil with percentages of at least $10 \%$ of sunflower and red palm oils ( $\mathrm{Xu}$ et al. (2014)). In the present study, the number of oils used for the adulteration study is higher than the number of adulterant oils mentioned in the NMR studies (Smejkalova and Piccelo, 2010; Agiomyrgianaki et al., 2010; Xu et al., 2014). It seems that measuring $\mathrm{T}_{2}$ by $\mathrm{LF}{ }^{1} \mathrm{H} \mathrm{NMR}$ and determining continuous $\mathrm{T}_{2}$ distribution help with olive oil adulteration detection where the adulterant oil percentage is economically significant. Because $\mathrm{LF}^{1} \mathrm{H}$ NMR is a non-destructive method, samples of $L F{ }^{1} \mathrm{H}$ NMR measurements could be used for further analysis by other methods. Besides this, it is also possible to compare and combine the results of LF ${ }^{1} \mathrm{H}$ NMR with the results obtained by UV-Vis in detecting the adulteration of olive oil.

\section{CONCLUSION}

The detection of olive oil adulteration was shown by $L F{ }^{1} \mathrm{H}$ NMR relaxometry and UV-Vis spectroscopy upon blending three olive oil samples having different oleoyl acyl contents with various edible oils. Bi-exponential fitting of the $\mathrm{T}_{2}$ data indicate that difference in oleoyl acyl contents of olive oil samples is an important factor in following representative unique signals of adulterated olive oils. When the three olive oil samples were mixed with castor oil, both $T_{21}$ and $T_{22}$ values became shorter as the volumetric ratio of olive oil to castor oil was changed from $2: 1$ to $1: 1$, and even further to $1: 2$. This was independent of which olive oil was used for preparing the mixtures. $\mathrm{T}_{2}$ relaxation values became longer as the volumetric ratios of the olive oils to corn oil were increased. However, the two values did not become as long as the ones belonging to the pure corn oil. Furthermore, UV-Vis spectroscopy was useful in detecting the adulteration of olive oil qualitatively. For example, when olive oil is adulterated with flax seed oil, it is possible to detect adulteration with the unique maximum absorbance at 320.0 $\mathrm{nm}$ of flax seed oil UV-Vis spectrum. In the possible adulteration of olive oil with either canola or soybean oil, the UV-Vis band around $298.0 \mathrm{~nm}$ of the canola and soybean oils might help with determining the adulteration. It seems that the application of LF ${ }^{1} \mathrm{H}$ NMR relaxometry by itself will not be sufficient to detect the adulteration of olive oil when an olive oil sample is mixed with almond, sesame, and grape seed oils in particular. It should also be emphasized that although $\mathrm{LF}{ }^{1} \mathrm{H}$ NMR is an easy method to operate, and in the current study LF NMR technique was employed in the adulteration detection of only three olive oil samples: California-Arbequina olive oil, California-Koroneiki olive oil, and FranceNyons olive oil. A higher of number of olive oil samples with different oleoyl acyl contents should be analyzed by the LF NMR technique in order to correlate, for example, $\mathrm{T}_{2}$ decaying curves to oleoyl acyl contents which might range from $65 \%$ up to $85 \%$. This might be useful in the adulteration detection of olive oil samples with different geographical origins. Combining non-destructive techniques of $\mathrm{LF}^{1} \mathrm{H}$ NMR and UV-Vis spectroscopy will be reliable and beneficial in detecting the adulteration of olive oil, which is not only an economic fraud but also can cause serious health problems. Combining such two different techniques also has the advantage of detecting the adulteration of olive oil above the lower critical limit (LCL) in an economic sense. Both methods have advantages of being easy to operate and non-destructive. Therefore, both methods could also be easily employed in controlling the virginity and purity of olive oil samples when olive oils are blended with some edible oils with different ratios.

\section{ACKOWLEDGMENTS}

The LF ${ }^{1} \mathrm{H}$ NMR relaxometry instrument at the Subsurface Energy Materials Characterization \& Analysis Laboratory (SEMCAL) at The Ohio State University was used, and therefore SEMCAL is gratefully acknowledged. The UV-Vis spectrophotometer was used at the Department of Food Science and Technology at The Ohio State University. The author is thankful to Dr. Melvin Pascall at the Department of Food Science and Technology of The Ohio State University for allowing the use of the UV-Vis spectrophotometer. The author declares no conflict of interest. 


\section{REFERENCES}

Agiomyrgianaki A, Petrakis PV, Dais P. 2010. Detection of refined olive oil adulteration with refined hazelnut oil by employing NMR spectroscopy and multivariate statistical analysis. Talanta 80, 2165-2171. http://dx.doi. org/10.1016/j.talanta.2009.11.024

Aursand IG, Gallart-Jornet L, Erikson U, Axelson DE, Rustad T. 2008. Water distribution in brine salted cod (Gadus morhua) and salmon (Salmo salar): A low-field ${ }^{1} \mathrm{H}$ NMR study. J. Agric. Food Chem. 56, 6252-6260. http://dx.doi. org/10.1021/jf800369n

Cerretani L, Motilva MJ, Romero MP, Bendini A, Lercker G. 2008. Pigment profile and chromatic parameter of monovarietal olive oils from different Italian cultivars. Euro. Food Res. Tech. 226, 1251-1258. http://dx.doi. org/10.1007/s00217-007-0651-7

Criado MN, Motilva MJ, Goni M, Romero MP. 2007. Comparative study of the effect of the maturation process of olive fruit on the chlorophyll and carotenoid fractions of drupes and virgin olive oils of Arbequina variety in Spain. Food Chem. 100, 748-755. http://dx.doi. org/10.1016/j.foodchem.2005.10.035

Dourtoglou VG, Dourtoglou T, Antopoulos A, Stefanou E, Lalas S, Poulos C. 2003. Detection of olive oil adulteration using principal component analysis applied on total and region fa content. J. Am. Oil Chem. Soc. 80, 203-208. http://dx.doi.org/10.1007/s11746-003-0677-1

Fuentes E, Baez ME, Bravo M, Cid C, Labra F. 2012. Determination of total phenolic content in olive oil samples by UV-visible spectrometry and multivariate calibration. Food Anal. Methods 5, 1311-1319. http://dx.doi. org/10.1007/s12161-012-9379-5

Giuliani A, Cerretani L, Cichelli A. 2011. Chlorophylls in olive and in olive oil: chemistry and occurrences. Crit. Rev. Food Sci. 51, 678-690. http://dx.doi.org/10.1080/1040839100 3768199

Gurdeniz G, Ozen B. 2009. Detection of adulteration of extravirgin olive oil by chemometric analysis of mid-infrared spectral data. Food Chem. 116, 519-525. http://dx.doi. org/10.1016/j.foodchem.2009.02.068

Hansen CL, Thybo AK, Bertram HC, Viereck N, van den Berg F, Engelsen SB. 2010. Determination of dry matter content in potato tubers by low-field nuclear magnetic resonance (LF-NMR). J. Agric. Food Chem. 58, 10300-10304. http:// dx.doi.org/10.1021/jf101319q

Hills BP. 2006. Applications of low-field NMR to food science. Annual Reports on NMR Spectroscopy 58, 177-230. http:// dx.doi.org/10.1016/S0066-4103(05)58004-9

Khattab R, Eskin M, Aliani M, Thiyam U. 2010. Determination of sinapic acid derivatives in canola extracts using high-performance liquid chromatography. J. Am. Oil Chem. Soc. 87, 147-155. http://dx.doi.org/10.1007/ s11746-009-1486-0

Lerma-Garcia M, Simo-Alfonso EF, Chiavaro E, Bendini A, Lercker G, Cerretani L. 2009. Study of chemical changes produced in virgin olive oils with different phenolic contents during an accelerated storage treatment. J. Agr. Food Chem. 57, 7834-7840. http://dx.doi.org/10.1021/ jf901346n

Lizhi H, Toyoda K, Ihara I. 2010. Discrimination of olive oil adulterated with vegetable oils using dielectric spectroscopy. J. Food Eng. 96, 167-171. http://dx.doi.org/10.1016/j. jfoodeng.2009.06.045

Martens HJ, Thybo AK. 2000. An integrated microstructural, sensory and instrumental approach to describe potato texture. LWT_Food Sci. Technol. 33, 471-482. http://dx.doi. org/10.1006/fstl.2000.0688

Mendes TO, da Rocha RA, Porto BLS, de Oliveira MAL, dos Anjos VC, Bell MJV. 2015. Quantification of extra-virgin olive oil adulteration with soybean oil: a comparative study of NIR, MIR, and Raman spectroscopy associated with chemometric approaches. Food Anal. Methods 8, 2339-2346. http://dx.doi.org/10.1007/s12161-015-0121-y
Mínguez-Mosquera MI. 1997. Clorofilas y carotenoides en tecnología de alimentos. Secretariado de publicaciones de la Universidad de Sevilla, Sevilla.

Moyano MJ, Heredia FJ, Meléndez-Martínez AJ. 2010. The color of olive oils: the pigments and their likely health benefits and visual and instrumental methods of analysis. Comp. Rev. Food Sci. Food Saf. 9, 278-291. http://dx.doi. org/10.1111/j.1541-4337.2010.00109.x

Nunes, CA. 2014. Vibrational spectroscopy and chemometrics to assess authenticity, adulteration and intrinsic quality parameters of edible oils and fats. Food Res. Int. 60, 255-261. http://dx.doi.org/10.1016/j.foodres.2013.08.041

Ok, S. 2014. Fast screening of Turkish olive oil by NMR spectroscopy for geographical determination and discrimination purposes. Grasas Aceites 65, e024. http://dx.doi. org/10.3989/gya. 122413

Ok, S. 2016. Authentication of commercial extra virgin olive oils. J. Am. Oil Chem. Soc. 93, 489-497. http://dx.doi. org/10.1007/s11746-016-2797-6

Passaloglou-Emmanouilidou S. 1990. A comparative study of UV spectrophotometric methods for detection of olive oil adulteration by refined oils. Z. Lebensm. Unters. Forsch. 191, 131-134. http://dx.doi.org/10.1007/BF01202639

Provencher SW. 1982. A constrained regularization method for inverting data represented by linear algebraic of integral equations. Comput. Phys. Commun. 27, 213-227. http:// dx.doi.org/10.1016/0010-4655(82)90173-4

Riberio ROR, Marsico ET, Carnerio CS, Monteiro MLG, Junior CC, de Jesus EFO. 2014. Detection of honey adulteration of high fructose corn syrup by low field nuclear magnetic resonance (LF ${ }^{1} \mathrm{H}$ NMR). J. Food Eng. 135, 39-43. http:// dx.doi.org/10.1016/j.jfoodeng.2014.03.009

Roca M, Gallardo-Guerrero L, Mínguez-Mosquera MI, Rojas BG. 2010. Control of olive oil adulteration with copperchlorophyll derivatives. J. Agric. Food Chem. 58, 51-56. http://dx.doi.org/10.1021/jf902084d

Rohman A, Che Man YB. 2010. Fourier transform infrared (FTIR) spectroscopy for analysis of extra virgin olive oil adulterated with palm oil. Food Res. Int. 43, 886-892. http://dx.doi.org/10.1016/j.foodres.2009.12.006

Smejkalova D, Piccolo A. 2010. High-power gradient diffusion NMR spectroscopy for the rapid assessment of extravirgin olive oil adulteration. Food Chem. 118, 153-158. http://dx.doi.org/10.1016/j.foodchem.2009.04.088

Torrecilla JS, Rojo E, Domínguez JC, Rodríguez F. 2010(a). Linear and nonlinear chemometric models to quantify the adulteration the adulteration of extra virgin olive oil. Talanta 83, 404 409. http://dx.doi.org/10.1016/j.talanta.2010.09.048

Torrecilla JS, Rojo E, Domínguez JC, Rodríguez F. 2010(b). A novel method to quantify the adulteration of extra virgin olive oil with low-grade olive oils by UV-Vis. J. Agric. Food Chem. 58, 1679-1684. http://dx.doi.org/10.1021/ jf903308u

Xu Z, Morris RH, Bencsik M, Newton MI. 2014. Detection of virgin olive oil adulteration using low field unilateral NMR. Sensors 14, 2028-2035. http://dx.doi.org/10.3390/s140202028

Yang H, Irudayaraj J. 2001. Comparison of near-infrared, Fourier transform-infrared, and Fourier transform-Raman methods for determining olive pomace oil adulteration in extra virgin olive oil. J. Am. Oil Chem. Soc. 78, 889-895. http://dx.doi.org/10.1007/s11746-001-0360-6

Zabaras D. 2010. Olive oil adulteration with hazelnut oil and analytical approaches for its detection. In: Preedy VR, Watson RR (ed) Olives and olive oil in health and disease prevention. Academic Press, London, pp. 441-450. ISBN: 978-0-12-374420-3

Zamora R, Alba V, Hidalgo FJ. 2001. Use of high-resolution ${ }^{13} \mathrm{C}$ nuclear magnetic resonance spectroscopy for the screening of virgin olive oils. J. Am. Oil Chem. Soc. 78, 89-94. http:// dx.doi.org/10.1007/s11746-001-0225-z

Zhang A, Wan L, Wu C, Fang Y, Han G, Li H, Zhang Z, Wang H. 2013. Simultaneous determination of 14 phenolic compounds in grape canes by HPLC-DAD- UV using wavelength switching detection. Molecules 18, 14241-14257. http://dx.doi.org/10.3390/molecules 181114241 